\title{
Chinese Emotional Two-character Word Processing in Sentence Reading*
}

\author{
Jiaming Fang \\ School of Foreign Language, Dalian University of Technology, China \\ Degao Li \\ College of Chinese Language and Literature, Qufu Normal University, China \\ Shuo Cao \\ School of Foreign Language, Dalian University of Technology, China
}

\begin{abstract}
Compared to the processing of the words alone, the processing of Chinese two-character words in sentences will be closer to a natural scenario, and the understanding of the sentence will be influenced by both linguistic contexts and the non-linguistic contexts. This study, in a moving-window self-paced word-by-word sentence reading task, experimentally explored the processing of Chinese sentences with emotional two-character words using reversible words and reaction time as materials and index respectively. The experimental results showed that emotional words may facilitate the processing of its following two words; there might exist subsequent processing in the third word behind the emotional word; there might exist lexical access and whole-word access, processing of morpheme positioned information in the processing of Chinese two-character words in sentence reading; the processing of Chinese two-character words may be similar with that of word alone. This study expands the research of Chinese emotional two-character words processing.
\end{abstract}

Index Terms - emotion, affective sentence, Chinese two-character word, reversible word

\section{INTRODUCTION}

Researches on the processing of Chinese two-character words can further study the structure of Chinese mental dictionaries (Peng, Li \& Liu, 1994), and there have been many researches about it. However, concerning the structure of the access representation of Chinese two-character words, there are different views. And there are less studies on the structure of the access representation of Chinese emotional two-character words, which are closely related with human life. This study researched the processing of Chinese emotional two-character words in sentence reading context.

\section{A. Chinese Two-character Words}

According to Sandra (1994), multi-morpheme words refer to words that can be decomposed into two or more morphemes in word formation. The two-character word refers to a word that can be decomposed into two morphemes in word formation. According to Caramazza, Hillis, Rapp and Romani (1990), there were currently three main points of view on the processing of multi-morpheme words: the view of whole word accessibility, the view of morpheme accessibility and the view of mixed accessibility. The view of whole-word accessibility held that multi-morpheme words were represented in the whole-word form in mental dictionaries, with no separate morpheme representation. This type of lexical process involved directly activating the corresponding word representations by stimulus input. The view of morpheme accessibility believed that multi-morpheme words were represented by decomposed morphemes in mental dictionaries. For recognition, the input of the whole word was first decomposed into morpheme units before the processing was completed by the accessibility of morpheme representation. In comparison, the view of mixed access claimed that both morphemes and whole words may be units in the representation of accessibility. Peng, Ding and Wang (1999) mentioned that the processing of morpheme units played a certain role in processing, but it was not a necessary stage for lexical processing. They pointed out that the access to familiar words was achieved through whole words while the access to unfamiliar words was achieved through decomposed morphemes.

For the processing of multi-morpheme words, many studies have been carried out. For example: Bian, Cui and Yan (2010) claimed that if recognized in sentence reading, words would be processed in a more natural reading scenario. And they also found evidence in two experiments on multi-morpheme morphological representation to support the view of morpheme access. Peng et al. (1999) suggested that for lexical processing, there was indeed an activation of morpheme units, but this was not a necessary stage for lexical processing. The lexical access and the whole-word access had different functions in the processing. The lexical access mainly played the role of activation, while the whole-word

\footnotetext{
${ }^{*}$ This work was supported by the National Social Science Foundation of China under Grant Number 19BYY088. Shuo Cao is the corresponding author.
} 
access performed fine processing of words. Peng, Li and Liu (1994), by using the repeated activation paradigm, demonstrated the research model of Chinese compound words and simple words. The experimental results supported the hypothesis of morpheme storage.

Studies on the processing of Chinese two-character words are generally carried out by comparing with reversible words. Ding and Peng (2006) defined reversible word as a special form of Chinese word formation, and its structural form is AB-BA (such as “工人 worker”, “人工 manual”). Peng et al. (1999) presented that Chinese reversible words are characterized by two characters that make up a two-character word which are identical in shape and pronunciation, but oppositely positioned, thus causing a change in the meaning of the morpheme or the whole word. Based on the characteristics of Chinese reversible words, using reversible words as research materials can control the morpheme frequency, word frequency, stroke number and parts of speech, and facilitate the exploration of the role and relationship between morphemes and whole-words in word processing. Shi et al. (2016) suggested that cognitive conflict would cause the state of tension and imbalance, which may show additional factor in processing of reversible words. This study, following this research line, used reversible words to explore the processing of emotional words in sentences.

A wide range of studies on word processing in sentence reading context were also conducted. Li (2000) argued that compared with the word alone, if placed in a sentence, the processing of the word will be fundamentally changed due to the rapidly emerging linguistic context. In this kind of language processing, the promotion effect of higher-level processing on lower-level processing or previous processing on subsequent processing was reflected in the contextual effect. As can be seen, in the research of the processing of multi-morpheme words in sentence reading, the context is a significant factor.

\section{B. Sentence Reading and Emotional Context}

Zhao (2009) pointed out that in sentence reading, the factors that influence lexical processing can be divided into two categories: linguistic context factors and non-linguistic context factors.

Regarding these two factors, there were a lot of discussions. For example, according to Zhu (1991), there were two distinct views on the stage in which context information exerted an influence on the processing of lexical processing. "Before the processing", that is, context information played a role in the processing before the extraction of mental lexicons completed, thereby facilitating the completion of these processes; the other was "after the processing", that is, context information played a role after the extraction of mental lexicons was completed, and it would only further select and refine the word information before being integrated into the meaning of the sentence. Moreover, Zhu (ibid.) also studied the contextual effect of Chinese sentence on lexical processing. The results of the study indicated that the type of sentence context, the intensity of the context's restriction on the target word, the word frequency of the target word and the number of strokes all had a significant effect on lexical processing; Gong (2009), exploring the effects of emotional activation in the reading of Chinese sentences using rapid emotional activation paradigm, confirmed that there was indeed an activation effect of emotions which was shown by a shorter fixation time. Zhang and Li (2005), expounded their research on the emotional initiation effect by evaluating the classification task with color pictures as the initial stimulus and Chinese two-character words as the target stimulus. The results confirmed that there was still a significant emotional activation effect when the activation and target stimuli were different in terms of material type. Kintsch and Mross (1985) followed the classical language processing model believing that the processing of newly emerging words in sentence understanding required three stages: lexical access, lexical selection, and lexical integration, and more importantly, lexical processing needed to reach the stage of word integration before establishing a unified meaning of sentences. As Wang et al. (2007) mentioned that the processing of a single word may be more biased toward the processing of words and less emotionally processed. This experiment explored the processing of Chinese two-character words in sentences reading in order to balance the processing of word and emotion.

Based on the above, two questions need to be further explored: (1) In what ways do emotional words in sentences influence sentence comprehension? (2) with which path is the processing of Chinese two-character words in sentence reading achieved? Morpheme access or whole-word access? To answer these two questions, this study used a behavior experiment, with a moving-window self-paced word-by-word sentence reading task. For the experiment, there are two hypotheses: (1) the participants have a stronger reaction to emotional words; (2) the processing of Chinese two-character words in sentence reading includes morpheme access as well as the whole-word access.

\section{METHODOLOGY}

To identify the processing mechanism of Chinese emotional two-character words in sentence reading in a contrastive manner, sentences without emotional words and reversible words such as “医生检查了他的眼白, 发现上面布满了红 血丝(The doctor examined the whites of his eyes and found that they were covered with red blood)" were employed. The experiment used a moving-window self-paced word-by-word sentence reading task. A 2 (words, reversible words) $\times 2$ (emotional words, non-emotional words) within-subject experiment was designed. E-prime 3.0 was used to present stimuli and record the participants' key-press reactions.

\section{A. Participants}

Ninety six $($ male=36; female=60; mean age=19.5 $)$ undergraduates from the Translation Department of Qufu Normal 
University participated in this experiment. They were divided into 8 groups, with 12 in each group. Their eye sights or corrected eye sights were within the normal range, and no one had dyslexia. After the experiment, each participant received 20 yuan as a reward.

\section{B. Materials}

In the experiment, seventeen pairs of Chinese words were selected, as shown in Table1.

The word frequency, character frequency, and strokes of these Chinese reversible words were all controlled. Three of 17 pairs were emotional words, namely “爱心(love), 心爱(beloved)”, “醉心(obsessed), 心醉(enchanted)”, “虚心 (modest), 心虚(afraid of being found out)”. For the selection of the Chinese emotional words used in the experiment, this study referred to the study by Wang et al. (2007), and the words used in this experiment were emotional words - describing the state of emotion directly, instead of affective words-judging the emotional colors through the meaning of words. Among all the Chinese reversible words used in this experiment, there was a pair of Chinese reversible words with different pronunciations, “长生(chang sheng)" and “生长(sheng zhang)". The difference in pronunciation of a pair of Chinese reversible words is due to the polyphonic characters in Chinese. As for the issue whether the different pronunciations produced after this word order was reversed during the reading of the sentences had additional impact, this experiment did not take corresponding measures. This research retained this pair of words and believed it would not affect the result because the sentences containing such situations accounted for a very small proportion (only $0.033 \%$ ) of the total experimental sentences.

TABLE 1

EXPERIMENTAL MATERIAL

\begin{tabular}{|c|c|c|}
\hline number & word & reversible word \\
\hline 1 & 膏药(medicinal paste) & 药膏(ointment) \\
\hline 2 & 头骨(skull) & 骨头(bone) \\
\hline 3 & 皮肉(skin and flesh) & 肉皮(pork skin) \\
\hline 4 & 长生(long life) & 生长(grow up) \\
\hline 5 & 口气(tone) & 气口(gas port) \\
\hline 6 & 口疮(aphthous stomatitis) & 疮口(sore-opening) \\
\hline 7 & 脉动(pulsating) & 动脉(artery) \\
\hline 8 & 国民(national) & 民国(the Republic of China) \\
\hline 9 & 子弟(children) & 弟子(disciple) \\
\hline 10 & 民居(dwellings) & 居民(inhabitant) \\
\hline 11 & 药方(prescription) & 方药(the Chinese medicine) \\
\hline 12 & 眼白(the white of the eye) & 白眼(supercilious look) \\
\hline 13 & 酒药(Chinese yeast) & 药酒(medicinal liquor) \\
\hline 14 & 近亲(close relative) & 亲近(be on intimate terms with) \\
\hline 15 & 爱心(love) & 心爱(beloved) \\
\hline 16 & 醉心(obsessed) & 心醉(enchanted) \\
\hline 17 & 虚心(modest) & 心虚(afraid of being found out) \\
\hline
\end{tabular}

These 17 pairs of Chinese reversible words formed a total of 60 Chinese sentences, with the sentence length being basically the same. Among the sentences used in the experiment, the target words in 42 sentences (70\% of the total experimental sentences) were at the end of the first half of the sentence. Zhong et al. (2012) pointed out that in the processing of sentence reading comprehension, readers related an incoming Chinese two-character sentence-end word to the preceding input about $150 \mathrm{~ms}$ after its presentation before establishing the sentence meaning. Just and Carpenter (1980) presented that the end of the clause was where semantic integration of words within the clause and integration with prior discourse was made. The structure of the sentence used in this experiment did not exclude the following case: the establishment of sentence meaning at the end of the sentence caused the reaction time of the target word being longer. Simon and Sascha (2018) reported that syntactic boundaries may trigger the allocation of additional attention resources, thus extending the reading time and possibly leading to rereading of earlier parts of the text. However, this experiment aimed to make different types of horizontal comparisons for each word. Therefore, the structure of the experimental sentence will not affect the experimental results.

Fifteen college students rated the experimental and filling sentences for readability (1 was for the lowest readability, and 7 for the highest readability). The retained sentences were all rated higher than 5 (see Appendix).

$\mathrm{Li}$ et al. (2015) mentioned that the position and way of showing emotional words on the computer screen will influence the processing of emotional words. In this experiment, all Chinese two-character words were presented in the center of the computer display, with the same font, color, and size on the same background, effectively avoiding the possible influence of the presentation position and presentation method. 


\section{Experimental Procedure}

After the participants entered the laboratory and sat down, they were shown the following instructions on the computer display screen:

同学你好!

请你集中注意力阅读句子。

句子中的词汇将逐个在屏幕呈现。

在充分理解所看到词语的前提下, 尽可能快速地按 $\mathrm{f}$ 键, 或 $\mathrm{j}$ 键呈现下一词。

阅读句子后, 有两种情况:

1、该句后面没有问题，按 $\mathrm{f}$ 键或者 $\mathrm{j}$ 键进行下一句子阅读即可。

2、该句后面有一个关于句子的选择题, 如果选择左边的答案, 按 $\mathrm{d}$ 键; 右边的答案, 按 $\mathrm{k}$ 键。

（如果没有疑问，请按 q 键开始）

Hello classmates!

Please read the sentences carefully.

Sentences will be shown word by word in the screen.

Fully understand the word, and press "f", or " $\mathrm{j}$ " as soon as possible to go on reading. After reading the sentence, there are two situations:

1. If there is no question, just press " $\mathrm{f}$ " or " $\mathrm{j}$ " to see the next sentence.

2. If there is a multiple-choice question about the understanding of sentence you have just read before, press " $\mathrm{d}$ " to choose the answer on the left of the screen, or " $\mathrm{k}$ " on the right.

(If you have no questions, please press "q" to start.)

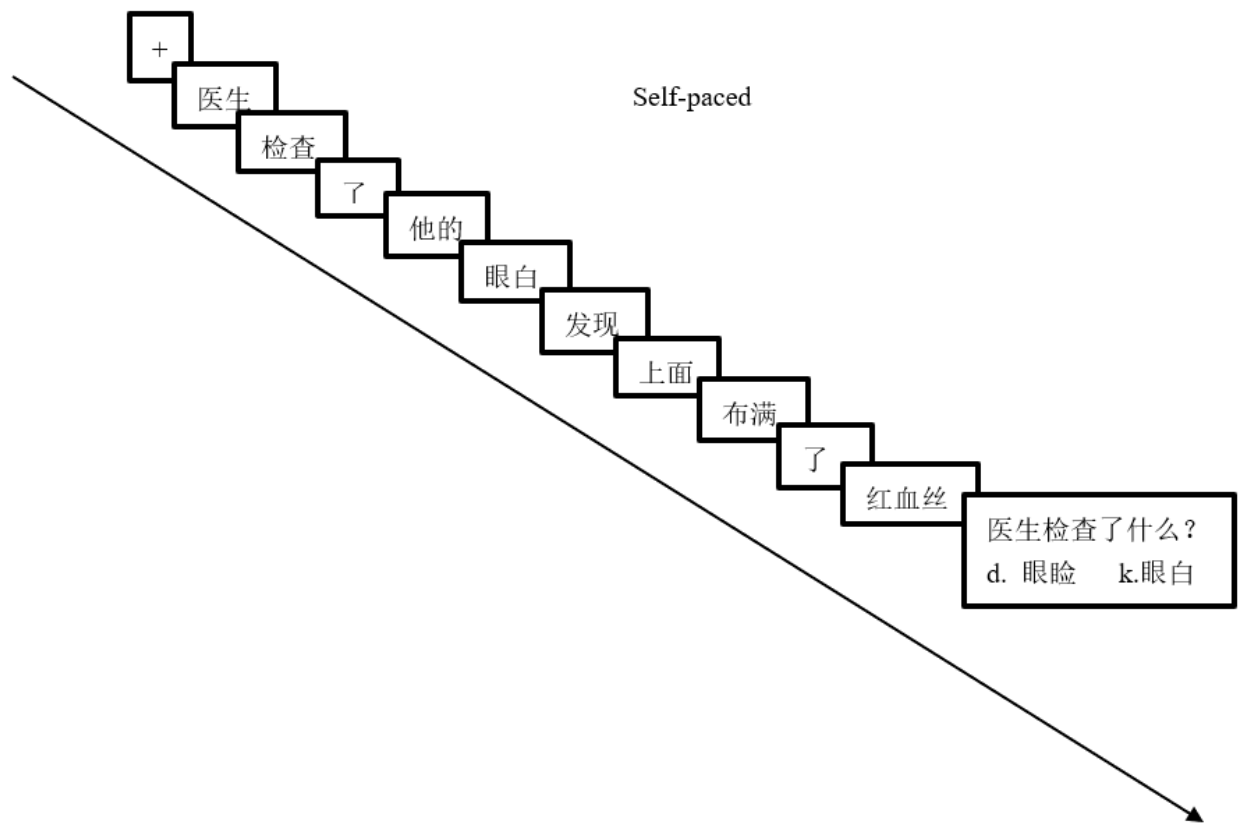

Figure 1. the Procedure of One Trail in Experiment

The participants were instructed to concentrate on the task to understand the sentences as quickly as possible, before answering the questions that would appear after the sentences (Answering the questions will draw the participant's attention on the sentence reading.). As shown in Fig. 1, the experiment procedure was as follows: a "+" fixation point was first displayed in the center of the computer screen for $800 \mathrm{~ms}$. Then, a Chinese word (Courier New, black, No. 12) appeared in the center of the screen (all experimental materials were presented on the computer display in black on white background). Each time after the participant finished reading a word, he or she pressed the "fo" or " $\mathrm{j}$ " within $5000 \mathrm{~ms}$. Then the next word appeared, and at the same time, the previous word disappeared. After responding to the final word of a sentence, there was a multiple-choice question (the probability of occurrence of a choice question was $50 \%$ ). The participant pressed " $d$ " to select the answer appearing on the left of the screen, and pressed " $k$ " to select the answer appearing on the right of the screen. Before the experiment formally began, the participants had twelve sentences to practice. The whole experiment lasted about fifteen minutes.

The experimenter collected the reaction time when the participants read the target words and the following words separately. The accuracy of the participants' answers was also recorded.

\section{RESULTS ANALYSIS}


SPSS20.0 was used for statistical analysis. Data were excluded for incorrect answers, and for the time of single fixation less than 80 milliseconds or more than 1200 milliseconds. The average and standard deviation of the participants' reaction time on each word was shown below (see Table 2).

TABLE 2

\begin{tabular}{|c|c|c|c|c|c|c|c|c|c|}
\hline & & \multicolumn{2}{|c|}{ TW } & \multicolumn{2}{|c|}{ FWBTW } & \multicolumn{2}{|c|}{ SWBTW } & \multicolumn{2}{|c|}{ TWBTW } \\
\hline & & $M$ & $S D$ & $M$ & $S D$ & $M$ & $S D$ & $M$ & $S D$ \\
\hline \multirow{2}{*}{ NEC } & Word & 311 & 79 & 375 & 130 & 333 & 72 & 348 & 130 \\
\hline & Reversible word & 339 & 95 & 397 & 147 & 371 & 100 & 340 & 86 \\
\hline \multirow{2}{*}{ EC } & Word & 303 & 82 & 301 & 79 & 294 & 72 & 303 & 79 \\
\hline & Reversible word & 308 & 75 & 292 & 60 & 331 & 127 & 382 & 226 \\
\hline
\end{tabular}

PARTICIPANT'S REACTION TIME ON EACH WORD (MS)

Notes: TW=target word; FWBTW= first word behind the target word; SWBTW= second word behind the target word; TWBTW= third word behind the target word; $\mathrm{NEC}=$ non-emotional condition; $\mathrm{EC}=$ emotional condition.

After the screening of the data, participant analysis was conducted. The analysis of TWs and the first three words behind TWs was shown as follows: for TWs: the main effect of emotion was significant $\left(F_{1}(1,31)=5.83, p=.022, \eta_{p}{ }^{2}\right.$ $=.158)$; the main effect of the word was significant at edge $\left(F_{l}(1,31)=3.07, p=.090, \eta_{p}^{2}=.090\right)$; the interaction between emotion and word was not significant $\left(F_{1}(1,31)=2.38, p=.133, \eta_{p}{ }^{2}=.071\right)$. Participants' reaction time to TWs under non-emotional conditions (NEC) ( $(M=325 \mathrm{~ms}, S E=14 \mathrm{~ms}$ ) was significantly longer than that to TWs under emotional conditions $(\mathrm{EC})(M=305 \mathrm{~ms}, S E=13 \mathrm{~ms})$. Participants' reaction time to word under the word condition (WC) $(M=307 \mathrm{~ms}, S E=13 \mathrm{~ms})$ tended to be shorter than that to word under reversible word condition (RWC) $(M=323 \mathrm{~ms}, S E=14 \mathrm{~ms})$.

For FWBTWs: the main effect of emotion was significant $\left(\left(F_{1}(1,31)=37.53, p=.00, \eta_{p}{ }^{2}=.548\right)\right.$; the main effect of words was not significant $\left(F_{1}(1,31)=.19, p=.665, \eta_{p}{ }^{2}=.006\right)$; the interaction between emotion and word was not significant $\left(\left(F_{l}(1,31)=1.17, p=.287, \eta_{p}{ }^{2}=.037\right)\right.$. Participants' reaction time to FWBTWs under NEC $(M=385 \mathrm{~ms}$, $S E=20 \mathrm{~ms})$ was significantly longer than that to FWBTWs under EC ( $M=296 \mathrm{~ms}, S E=11 \mathrm{~ms})$.

For SWBTWs: the main effect of emotion was significant $\left(F_{1}(1,31)=6.80, p=.014, \eta_{p}{ }^{2}=.180\right)$; the main effect of word was significant $\left(F_{1}(1,31)=11.68, p=.002, \eta_{p}{ }^{2}=.274\right)$; the interaction between emotion and word was not significant $\left(F_{1}(1,31)=.005, p=.946, \eta_{p}{ }^{2}=.000 ;\right)$. Participants' reaction time to SWBTWs under NEC $(M=325 \mathrm{~ms}$, $S E=14 \mathrm{~ms})$ was significantly longer than that to SWBTWs under EC ( $M=312 \mathrm{~ms}, S E=15 \mathrm{~ms})$; the reaction time of the participants to SWBTWs under WC $(M=314 \mathrm{~ms}, S E=11 \mathrm{~ms})$ was significantly shorter than that to SWBTWs under RWC $(M=351 \mathrm{~ms}, S E=16 \mathrm{~ms})$.

For TWBTWs: The main effect of emotion was not significant $\left(F_{l}(1,31)=.00, p=.947, \eta_{p}{ }^{2}=.000\right)$; the main effect of the word was significant at edge $\left(F_{l}(1,31)=2.94, p=.097, \eta_{p}^{2}=.087\right)$; the interaction between emotion and word was significantly marginal (see Figure 2$)\left(F_{1}(1,31)=4.06, p=.053, \eta_{p}{ }^{2}=.116\right)$. Statistical analysis of simple effect showed that there was no significant difference between the reaction time to TWBTWs under the non-emotional word condition (NE-WC) and that to TWBTWs under non-emotional reversible word conditions (NE-RWC) $\left(t_{(31)}=0.345, p\right.$ $=.732$ ); the participants' reaction time to TWBTWs under the condition of emotional word (E-WC) was significantly shorter than that to TWBTWs under the condition of emotional reversible words $(\mathrm{E}-\mathrm{RWC})\left(t_{(31)}=-2.199, p=.035\right)$. 


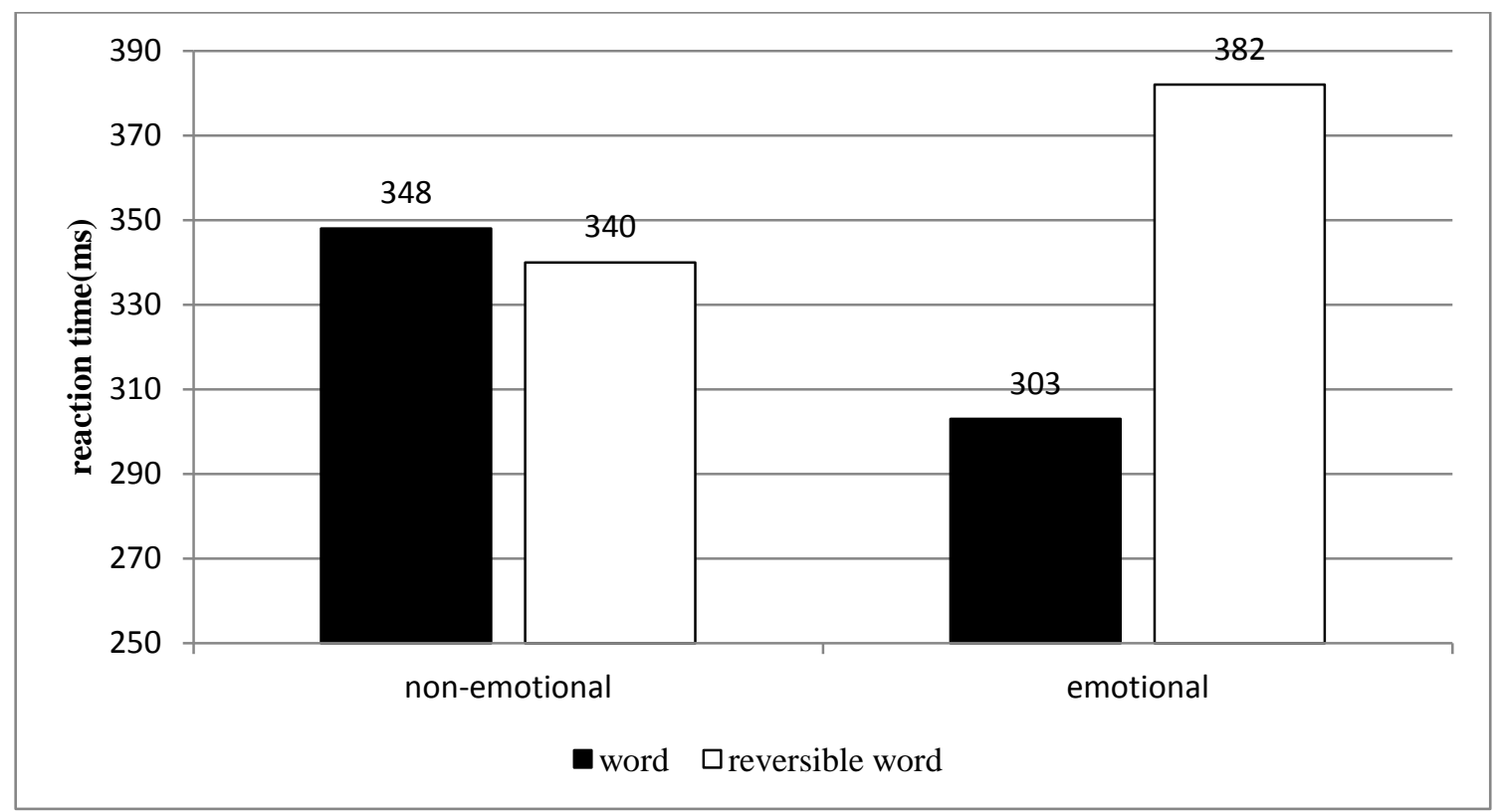

Figure 2. Reaction Time of TWBTWs in EC

\section{DISCUSSION}

This experiment explored the processing of Chinese emotional two-character words in sentence reading. Through statistical analysis of the reaction time of the participants to target words, and its following three words, this paper researched the influence of emotion on sentences comprehension and the processing path of Chinese two-character words in sentence reading.

The experimental results confirmed the hypotheses that (1) participants have a stronger reaction to emotional words; (2) the processing of Chinese two-character words in sentence reading includes morpheme access as well as the whole-word access. In addition, this study also found that there may exist subsequent processing of emotional words in TWBTWs and the processing of morpheme's position information.

\section{A. Emotion Effects}

Data analysis showed that the main effect of emotion of TWs, FWBTWs and SWBTWs was significant; meanwhile, the main effect of emotion of TWBTWs was not significant.

Analysis in terms of the main effect of emotion confirmed the hypothesis (1) the participants have a stronger reaction to emotional words. Human beings belong to emotional creatures. For the emotional words located in the target word position, the participants will be more sensitive to them than to other words. Emotional words can affect people's emotions, thereby accelerating the information extraction process of word processing, resulting in shorter reaction time than that of non-emotional words. For FWBTWs and SWBTWs, emotional word provided stronger expectations than non-emotional words, so the participants' reaction time to FWBTWs and SWBTWs was shortened. For TWBTWs, the expectation provided by the emotional word was not so strong when it arrived here, so it did not bring about a shortened reaction time.

To sum up, emotional words may have a promoting effect on the processing of the Chinese two-character words following the target word, but this facilitating effect may only exist in the following two words behind the target word.

\section{B. Word Effects}

Data analysis showed that for the target word, the main effect of word was significant at edge; the main effect of word of FWBTWs was not significant; the main effect of word of SWBTWs was significant; the main effect of word of TWBTWs was significant at edge.

Analysis in terms of the main effect of word confirmed the hypothesis (2) the processing of Chinese two-character words in sentence reading includes morpheme access as well as the whole-word access. During the processing of TWs, the participants were not strongly aware of the difference between the word and the reversible word and therefore, the participants were not aware of the difference between the word and the reversible word when they processed FWBTWs. It may prove that morpheme access was the main processing path during this period when words are processed in these two positions. Zhou, Wang and Luo (2007) supported the theory of emotional intervention through experiments, claiming that the attention to emotional information will weaken the processing of the semantic information. According to him, the attention to emotional information interfered with the processing of the semantic information with the result that participants did not distinguish between words and reversible words when reading TWs and FWBTWs. However, the present study didn't provide supporting evidence, because there was no significant interaction between emotion and 
word in TWs and FWBTWs. Furthermore, the proportion of non-affective sentences was higher than that of affective sentences in the experimental sentences, which means there was no strong evidence to prove that the attention to emotional information weakened the processing of semantic information. Therefore, in the processing of TWs and FWBTWs, the main process of TWs was mainly accessed by morpheme access. When the participants processed SWBTWs, the reaction time to the Chinese reversible word was longer than that to the word, an indication that the participants mainly processed the words by whole-word access in this period, or processed the positioned information of the morpheme. When the participant processed TWBTWs, there was no significant difference in the reaction time between the reversible word and the word. At this point, the morpheme access was mainly performed or the processing of TWs has been already completed. According to the processing of SWBTWs and TWBTWs, this study believed that the positioned information of morpheme was processed at the time when the SWBTWs were processed. If the whole-word access was performed at the time of processing SWBTWs, there was no reason that the participants were not aware of the anomaly in the position of the target word when reading TWBTWs. According to Peng et al. (1999), the processing of morpheme's position information lagged behind that of morpheme unit itself. Therefore, this paper suggested that the participants might process the morpheme's position information when reading SWBTWs.

Another finding of this research was that the processing of the Chinese two-character words in sentences may be similar with that in word form alone. Peng et al. (1999) used Chinese reversible words as the priming material in the semantic priming paradigm, to explore the processing of Chinese reversible words. In contrast, the experiment in this research was conducted under the condition of sentence reading. However, based on the analysis of the processing of these four words, the target word and its following three words, the order in which the whole-word access and the morpheme access playing the main role in sentence reading was basically the same as that in words alone, as shown in Peng's study, that is, morpheme access occurred first (then the processing of the position information of the morphemes optionally) before finally the whole-word was accessed. Based on the above discussion, it can be concluded that the processing of the Chinese two-character words in sentences was similar with that in word form alone. It means morpheme access was the main access initially before whole-word access begins to play its vital role.

\section{The Interaction between Emotion and Word}

Data analysis showed that for TWs, FWBTWs, SWBTWs, the interaction of two factors (emotion and word) was not significant; only the interaction between the emotion and word of TWBTWs was significant. The participants' reaction time to TWBTWs under E-WC was significantly shorter than that to TWBTWs under E-RWC. With regard to the reaction time to TWBTWs under NEC, no significant difference was identified between WC and RWC.

According to Shi et al. (2016) this happened as a subsequent processing due to the state of tension and imbalance. So, emotional words in this experiment may trigger such tension and imbalance state, leading to a subsequent later processing. The difference between the processing of the TWBTWs under E-WC and E-RWC could be explained in this way: the conflict caused by the reverse order of words led to an increased imbalance and tension state brought by emotional words. In this study, the participants faced and solved the conflict caused by such a reversed order of words. This was in line with the study by Peng (1999) who found that in the late stage of word processing, the processing of morpheme's position information played a role in word confirmation.

To sum up, there existed subsequent processing of emotional Chinese two-character words in TWBTWs, and the subsequent processing mainly involved the processing of the morpheme's position information.

\section{CONCLUSIONS}

This study attempted to examine the role of emotional words in sentences reading and the processing path of Chinese two-character words to further expand the research of processing of emotional Chinese two-character words. This study had several findings: in sentence reading, (1) emotional words may facilitate the processing of its following two words; (2) there might be a subsequent processing of TWBTWs; (3) morpheme access, whole-word access and processing of morpheme's position information were performed; (4) the processing of Chinese two-character words may be similar to that in word alone.

This study is conducive to people's interpersonal communication in daily life when Chinese emotional two-character words used, and it expands the research of Chinese emotional two-character words processing.

However, the emotional words used in this experiment all have the character “心(xin)". Whether this special structure has an influence needs to be further explored in the future with more lexical expressions of emotion. 


\section{APPENDIX}

他在伤口敷了一些亳药, 不一会便止痒消肿了。

考古发现了一个完整的头骨, 考古学家将对其进行仔细研究。

医生开完了最后一个药方, 便收拾好下班了。

他去药店买了几贴药亳, 贴在肩上缓解关节疼痛。

她看着自己松驰的皮肉, 忽然感叹起岁月的流逝。

古代很多帝王都渴望长生, 但这是有悖于自然规律的。

他着急上火生了口疮, 现在疼得只能喝米粥。

他在车祸中伤到了肉皮, 所幸并无任何大碍。

他观察了石缝中幼苗的生长, 不禁感叹它旺盛的生命力。

人体有个部位叫做口气, 是中医为病人诊脉的一个地方。

老中医数着病人的脉动, 不由得暗自担心起来。

他患有严重的气口, 每天要刷很多次牙。

这首诗创作于国民时期, 具有极高的研究价值。

人民子弟兵对祖国和人民无限忠诚, 是我们的骄傲。

中青年民居忙于事业, 朝九晚五。

只要人人都献出一份爱心, 世界将会变得更加美好。

他很虚心地跟在后头, 不愿意抢任何人的风头。

他心醉于搞学术研究, 无暇顾及任何其他事情。

我心虚地向他解释, 这件事情与我毫无关系。

那蔚蓝的大海令人醉心, 似一片一望无际的宇宙。

他去药店买了几贴膏药, 贴在肩上缓解关节疼痛。

考古发现了一个完整的骨头, 考古学家将对其进行仔细研究。

桌子上的那瓶酒药, 是女儿从城里带回来的。

他在车祸中伤到了动脉, 经过抢救捡回了一条命。

医生为他开了一剂方药, 并叮嘱他按时按量服用。

古代很多帝王都渴望生长, 但这是有悖于自然规律的。

他着急上火生了疮口, 现在疼得只能喝米粥。

他患有严重的口气, 每天要刷很多次牙。

医生检查了他的白眼, 发现上面布满了红血丝。

人体有个部位叫做气口, 是中医为病人诊脉的一个地方。

他动不动就冲人翻眼白, 这一点着实令人厌恶。

它正在用舌头㖨口疮, 看起来十分痛苦。

他是陈式太极拳第 26 代嫡传弟子, 至今还每日向师傅请教。

中青年居民忙于事业，朝九晚五。

人民弟子兵对祖国和人民无限忠诚, 是我们的骄傲。

这首诗创作于民国时期, 具有极高的研究价值。

由于是亲近结婚, 他们的孩子都有遗传病症。

奶奶是我极其近亲之人, 我对她无话不说。

这是她最心爱的洋娃娃, 就连睡觉都要抱着它睡。

那蔚蓝的大海令人心醉, 似一片一望无际的宇宙。

他醉心于搞学术研究, 无暇顾及任何其他事情。

医生开完了最后一个方药, 便收拾好下班了。

他在伤口敷了一些药膏, 不一会便止痒消肿了。

桌子上的那瓶药酒, 是女儿从城里带回来的。

他在车祸中伤到了皮肉, 所幸并无任何大碍。

她看着自己松弛的肉皮, 忽然感叹起岁月的流逝。

他在车祸中伤到了脉动, 经过抢救捡回了一条命。

医生为他开了一剂药方, 并叮嘱他按时按量服用。

他动不动就冲人翻白眼, 这一点着实令人庈恶。

它正在用舌头称疮口, 看起来十分痛苦。

老中医数着病人的动脉, 不由得暗自担心起来。

医生检查了他的眼白, 发现上面布满了红血丝。

他观察了石缝中幼苗的长生, 不禁感叹它旺盛的生命力。

由于是近亲结婚, 他们的孩子都有遗传病症。

他是陈式太极拳第 26 代嫡传子弟, 至今还每日向师傅请教。

奶奶是我极其亲近之人, 我对她无话不说。

我虚心地向他解释, 这件事情与我毫无关系。

只要人人都献出一份心爱, 世界将会变得更加美好。

这是她最爱心的洋娃娃, 就连睡觉都要抱着它睡。

他很心虚地跟在后头, 不愿意抢任何人的风头。

\section{ACKNOWLEDGEMENTS}

This work was supported by the National Social Science Foundation of China under Grant Number 19BYY088. 


\section{REFERENCES}

[1] Bian, Q., Cui, L. \& Yan, G. L. (2010). Effects of the transposed morpheme on the Chinese sentence reading: Evidence from eye movement data, Psychological Research, 1, 29-35.

[2] Caramazza, A., H. Argye, E., R. Brenda, C. \& R. Cristina. (1990). The multiple semantics hypothesis: Multiple confusions? Cognitive Neuropsychology, 7.3, 161-189.

[3] Ding, G. Sh., Peng, D. L. (2006). Mental recognition of Chinese words in reverse order: The relationship between whole word processing and morphemic processing, Contemporary Linguistics, 1, 36-45+93-94.

[4] Dominiek, S. (1994). The morphology of the mental lexicon: Internal word structure viewed from a psycholinguistic perspective. Language and Cognitive Processes, 9.3, 227-269.

[5] Gong, Zh. (2009). The emotional priming effect in sentence reading: Evidence from eye movements. In: Abstracts of Papers of the Twelfth National Conference on Psychology, Jinan, Shandong Province, China, 6-8 November, 2009. Jinan: The Chinese Psychological Society, 218-219.

[6] Li, D. G., Ma, B. S. \& Liu, H. T. (2015). Association of affect with vertical position in L1 but not in L2 in unbalanced bilinguals. Frontiers in Psychology, 6, 1-12.

[7] Li, Q. (2000). The effects of sentence context in reading process, Journal of Beijing Normal University (Social Sciences), 3 , 124-129.

[8] Marcel, A. J. \& P. A. Carpenter. (1980). A theory of reading: from eye fixations to comprehension. Psychological review, 87.4, 329-354.

[9] Peng, D. L., Ding, G. Sh. \& Wang, Ch. M. (1999). The processing of Chinese reversible words-the role of morphemes in lexical access, Acta Psychologica Sinica, 1, 36-46.

[10] Peng, D. L., Li, Y. P. \& Liu, Zh. Zh. (1994). Identification of the Chinese two-character word under repetition priming condition, Acta Psychologica Sinica, 4, 393-400.

[11] Shi, L., Wu, X. G., Li, L. Y., Li, X. \& Pan, F. D. (2016). Positive or Negative? The Signal Function of Conflict Processing, Psychology: Techniques and Applications, 4, 204-208.

[12] Simon, P. T. R. \& S. Schroeder. (2018). The development of wrap-up processes in text reading: a study of children s eye movement. Journal of Experimental Psychology: Memory, and Cognition, 44.7, 1051-1063.

[13] Walter, K. \& E. F. Mross. (1985). Context effects in word identification. Journal of memory and language, 24.3, 336-349.

[14] Wang, Y. N., Zhou, L. M., Qu, Sh. \& Luo, Y. J. (2007). Implicitly processing of affective connotation of Chinese words: evidence from Event-Related Brain Potential, Journal of Beijing Normal University (Natural Science), 4, 466-470.

[15] Zhang, Q. \& Li, X. H. (2005). Affective Priming Effects under Two SOA Conditions, Chinese Journal of Applied Psychology, 2 154-159.

[16] Zhao, W. H. (2009), An ERP study on the processing of emotional words in sentences under emotional context. M.D. dissertation, Capital Normal University.

[17] Zhou, L. M., Wang, Y. N., Luo, Y. J. (2007). The temporal characteristics of emotional two-character word processing in implicit and explicit tasks. In: The Third National Conference on Brain and Cognitive Science and Brain Collection of Abstracts of International Symposium on Cognitive Science, Kunming, Yunnan province, China, 26 November to 6 December, 2007. Beijing: Progress in Biochemistry and Biophysics, 178.

[18] Zhong, W. F., Mo, L., Jin, H. \& Xu, G. P. (2012). The Timing of Sentence Meaning Establishment During Sentence Comprehension, Acta Psychologica Sinica, 6, 735-744.

[19] Zhu, X. P. (1991). The effect of Chinese sentence context on word recognition, Acta Psychologica Sinica, 2, 145-152.

Jiaming Fang was born in Shandong, China in 1998. She received her bachelor's degree from Qufu Normal University, China in 2020. She is currently a first-year graduate student majoring in linguistics in Dalian University of Technology.

Degao Li received his Ph.D in Psychology from South China Normal University, China in 2007. He is currently a professor in College of Chinese Language and Literature, Qufu Normal University, Shandong Province, China.

Shuo Cao received her Ph.D in Technologic Economic and Management from Dalian University of Technology, China in 2019. She is currently a professor in the School of Foreign Language, Dalian University of Technology, Liaoning Province, China. 